\title{
The Influence of Taurine on the Bile Acid Maximum Secretory Rate in the Guinea Pig
}

\author{
DOMINIQUE C. BELLI, LYSE-ANDRÉE FOURNIER, GUY LEPAGE, IBRAHIM M. YOUSEF, AND \\ CLAUDE C. ROY \\ Pediatric Gastroenterology Unit, Hôpital Ste-Justine and Clinique Universitaire de Pédiatrie, Departments of \\ Pediatrics, University of Montreal, Montreal, Québec, Canada and the University of Geneva,
}

Geneva, Switzerland

\begin{abstract}
In view of the effect of taurine feeding on the cholestasis induced by sulfated lithocholate in the guinea pig, it was of interest to explore the influence of taurine on the bile acid secretory maximum (SRm) of chenodeoxycholic acid and of its glycine and taurine conjugates. Bile acid secretory rate measured in response to stepwise increasing rates showed for chenodeoxcholic acid an SRm of $147 \pm 6 \mathrm{nmol} / \mathrm{min} / \mathrm{g}$ liver and any $\mathrm{SRm}$ that was higher $(p<0.01)$ for taurine than for glycine $(426 \pm$ 21 versus $327 \pm 24 \mathrm{nmol} / \mathrm{min} / \mathrm{g}$ liver). Pretreatment for 3 days with taurine $0.5 \%$ in drinking water led to a $70 \%$ increase of the SRm for chenodeoxycholic acid. Analysis of the biliary bile acids after supplemental taurine demonstrated a large increment of tauroconjugates and no change in the percent of free bile acids or of sulfated forms. Experiments with labeled chenodeoxycholic acid showed no difference in the distribution of radioactivity between total liver, blood, bile, and urine on and off taurine thereby suggesting that neither sinusoidal uptake nor translocation across the cell were factors responsible for the difference in SRm. Inasmuch as taurine feeding increased the SRm for glycine by $30 \%$ and for taurine by $25 \%$, it is suggested that taurine augments the canalicular excretion of bile acids that represents the rate-limiting step in the transfer of bile acids from blood into bile through a mechanism that cannot be explained only by a modification of the conjugation pattern (Pediatr Res 24: 34-37, 1988)
\end{abstract}

Abbreviations

Tm, transport maximum

SRm, maximum secretory rate

CDC, chenodeoxycholic acid

GCDC, glycochenodeoxycholic acid

TCDC, taurochenodeoxycholic acid

BASR, bile acid secretion rate

The mechanisms of bile formation and secretion have been the subject of intensive research for several decades and have begun to be well characterized (1-3). The effect of bile acids on bile flow has been traditionally explained by the combined osmotic effect of individual bile acid molecules and micelles (4).

Received July 28, 1986; accepted February 29, 1988.

Correspondence Claude C. Roy, M.D., Pediatric GI Unit, Hôpital Ste-Justine, 3175 Côte Ste-Catherine Road, Montreal, Quebec, Canada H3T 1C5.

D.C.B. was a research fellow of the Canadian Foundation of Cystic Fibrosis which supported this study by a Grant-in-aid jointly with the Medical Research Council of Canada (MT 4433).

${ }^{1}$ Presented in part at the 96th Annual Meeting of the American Pediatric Society, Washington, D.C., May 1986.

The authors thank Mrs. D. St-Cyr Huot for her secretarial assistance.
More recently, studies have demonstrated the influence of the structure of individual bile acids on bile flow as their pattern of conjugation, critical micellar concentration, and relative hydrophilicity influence bile flow and biliary lipid secretion (5-9).

The classical definition of Tm implies that a constant $\mathrm{Tm}$ rate is maintained in the face of increasing delivery of the substance above its Tm. These conditions cannot be satisfied with bile acids except for sulfates (10) because biliary bile acid secretion rate reaches a plateau and then declines with bile flow as the infusion rate of bile acids increases (11-13). In view of this limitation, Hardison coined the term bile acid SRm when the plateau is reached (12). The SRm is an important concept as it reflects the overall rate-limiting step in the transport of bile acids through the hepatocyte $(12,14-19)$. Although some authors have shown that conjugation increases the SRm in the rat (18), no one has yet examined the $\mathrm{SRm}$ in a species that like man conjugates its bile acids mainly with glycine.

Taurine fits the definition of a conditionally essential amino acid, because needs cannot be met when dietary intake is inadequate or when losses are excessive (20). Taurine has an effect on osmoregulation (21), on the brain and retina $(22,23)$, and probably on growth (24). However, conjugation with bile acids is its only metabolic reaction. The reported effects of this conjugation on biliary physiology are to increase bile flow (25) and bile acid pool through an increased synthesis (26), to decrease the cholestatic potential of monohydroxylated bile acids (25) and to improve fat absorption in patients with cystic fibrosis who have an abnormally high ratio of glycine over taurine conjugated bile acids (27).

The aim of our study was to determine if taurine could alter the SRm of CDC, the predominant bile acid of the guinea pig, and to ascertain whether this effect is dependent on a change in its conjugation pattern.

\section{MATERIALS AND METHODS}

Animals. Male guinea pigs aged 14 to 28 days and weighing 235-320 g were obtained from Charles River Inc. (La Prairie, Québec, Canada), housed in a temperature-controlled room $\left(22^{\circ}\right.$ C) with alternative $12 \mathrm{~h}$ light-dark cycles for at least $1 \mathrm{wk}$ before use and fed guinea pig food ad libitum with free access to water.

Chemicals. The bile acids used in this study, CDC, GCDC, and TCDC were purchased as the sodium salts from Calbiochem (La Jolla, CA) and no contaminants were detected by thin layer chromatography when large samples were analysed. $\left[{ }^{14} \mathrm{C}\right]$ labeled CDC (specific activity $50.5 \mathrm{mCi} / \mathrm{mmol}$ ) was obtained from New England Nuclear (Boston, MA). Taurine (Aldrich Chemical Co.) was purified and recrystallized as previously described (25).

Experimental design. Guinea pigs were maintained either on a normal diet, or guinea pig food with taurine $0.5 \%$ in drinking water for 3 days. On the experimental day the animals were 
anesthetized with $44 \mathrm{mg} / \mathrm{kg}$ ketamine hydrochloride (Ketalar, Parke Davis, Detroit, MI) and $2 \mathrm{mg}$ acepromazine maleate (Atravet, Ayerst, Montreal, Québec, Canada). A central catheter was then positioned in the superior vena cava after its introduction in the right external jugular vein. After laparotomy, a large polyethylene tubing (PE 50, Clay Adams, Parsippany, NJ) was introduced into the common bile duct and the gallbladder was ligated. Body temperature was maintained at $39.5 \pm 1.0^{\circ} \mathrm{C}$ by a temperature-controlled heating lamp with rectal probe.

In the first phase of the study, the endogenous bile acid pool was drained for $1 \mathrm{~h}$ in guinea pigs maintained on a normal diet. Estimation of the SRm of CDC and of its GCDC and TCDC conjugates was then carried out by infusing in stepwise increasing rates these bile acids dissolved in a $0.45 \% \mathrm{NaCl}$ solution containing $7.5 \%$ albumin. Each infusion rate was continued for $30 \mathrm{~min}$ and hepatic bile was collected continuously in 10-min aliquots. $\mathrm{CDC}$ was infused at rates of $0.4,0.6,0.8,1.0$, and $1.2 \mu \mathrm{mol} /$ $\mathrm{min} / 100 \mathrm{~g}$ body weight whereas the conjugates were infused at rates of $1.0,1.2,1.6,2.0,2.4$. The second part of the study involved guinea pigs with and without supplemental taurine. They were infused with CDC at a rate of 0.8 , with GCDC at 1.6 and TCDC at $2.0 \mathrm{~mol} / \mathrm{min} / 100 \mathrm{~g}$ body weight as these rates of infusion were those leading to the SRm established in the initial phase of the study. Neither hemoglobinuria nor evidence of hemolysis on blood smears was noted in response to these doses of bile acids. At the termination of the experiments the animals were killed and the rapidly removed livers did not reveal any histological changes.

To verify that the rate-limiting step for the secretion of bile acids was at the level of the bile canalicular membrane and not at that of the hepatic uptake, a set of experiments was conducted using labeled CDC after which the distribution of radioactivity was quantitated. $\mathrm{CDC}$ with ${ }^{14} \mathrm{C}-\mathrm{CDC}$-labeled was infused at a rate of $0.8 \mu \mathrm{mol} / 100 \mathrm{~g}$ body weight $/ \mathrm{min}$ in animals with or without a supplement of taurine. Thirty-min hepatic bile collections were obtained and on termination of the experiments blood was obtained from the vena cava and urine from the bladder before removing and weighing the livers.

Analyses. Bile flow was determined gravimetrically and total bile acids were measured enzymatically (28). The pattern of biliary bile acids was measured from $0.5 \mathrm{ml}$ of bile by gas-liquid chromatography. Free, glycoconjugated, and tauroconjugated bile acids were separated on thin-layer chromatography developed in a water/ $n$-propanol/diethylether/isoamylacetate/propionic acid (10:20:23:40:10 vol/vol) solution. The three silica bands corresponding to standards were scraped off and bile acids were extracted twice in acetic acid methanol (1:100) containing nordeoxycholic acid as internal standard. After alkaline hydrolysis of the glycoconjugated and tauroconjugated bile acids, the media were acidified and free bile acids were extracted twice with ethylacetate. Solvolysis was carried out on a measured aliquot of the ethylacetate extractant (29). Each of the six extracted bile fractions were then methylated and acetylated (30). Total and individual bile acids were quantified with a Hewlett Packard 5880 gas chromatograph using a 6 feet column packed with $2 \%$ $\mathrm{QF}_{1}$ on chromosorb W(HP) 100:120 mesh. Counting of ${ }^{14} \mathrm{C}$ CDC was carried out in $100 \mu \mathrm{l}$ of bile, whole blood, urine, and liver homogenate using Beckman Ready Solvent MP as scintillant, hydrogen peroxyde to reduce the quenching, and a Beckman LS 7500 liquid scintillation system (Beckman Instruments Inc., Palo Alto, CA).

Statistics. The means and SEM were calculated. The homogeneity of variance was checked by the Bartlett test (31). Student's $t$ test for parallel groups or repeated data were used when appropriate. An $\alpha<0.05$ was estimated as statistically significant.

\section{RESULTS}

BASR increased to a maximum of $147 \pm 6 \mathrm{nmol} / \mathrm{min} / \mathrm{g}$ liver in response to the infusion of CDC at a rate of $0.8 \mu \mathrm{mol} / \mathrm{min} /$
$100 \mathrm{~g}$ body weight: thereafter, it decreased progressively. The BASR reached a plateau of $327 \pm 24 \mathrm{nmol} / \mathrm{min} \mathrm{g}$ liver for GCDC infused at a rate of $1.6 \mu \mathrm{mol} / \mathrm{min} / 100 \mathrm{~g}$ body weight and of 426 \pm 21 in response to an infusion rate of 2.0 for TCDC (Fig. 1). The changes in bile flow observed during the infusion of bile acids were correlated with the changes in bile acid secretion in that the SRm and maximum bile flows were achieved at the same rate of infusion for the three bile acids (Fig. 1).

Results of the experiments carried out to test the effect of supplemental taurine on the bile flow and the BASR in response to $\mathrm{CDC}$ at an infusion rate of $0.8 \mu \mathrm{mol} / \mathrm{min} / 100 \mathrm{~g}$ body weight showed that taurine had no effect on bile flow but it increased $(p<0.01)$ the BASR from $129.7 \pm 3.3 \mathrm{nmol} / \mathrm{min} / \mathrm{g}$ liver to $222.6 \pm 20.1$ (Fig. 2). The profile of bile acids recovered from these animals indicates that taurine led to an increase in tauroconjugates and to close to a 5-fold decrease in the ratio $(6.4 \pm$ $1.0 \rightarrow 1.4 \pm 0.3$ ) of glyco over tauroconjugates (Fig. 3). The
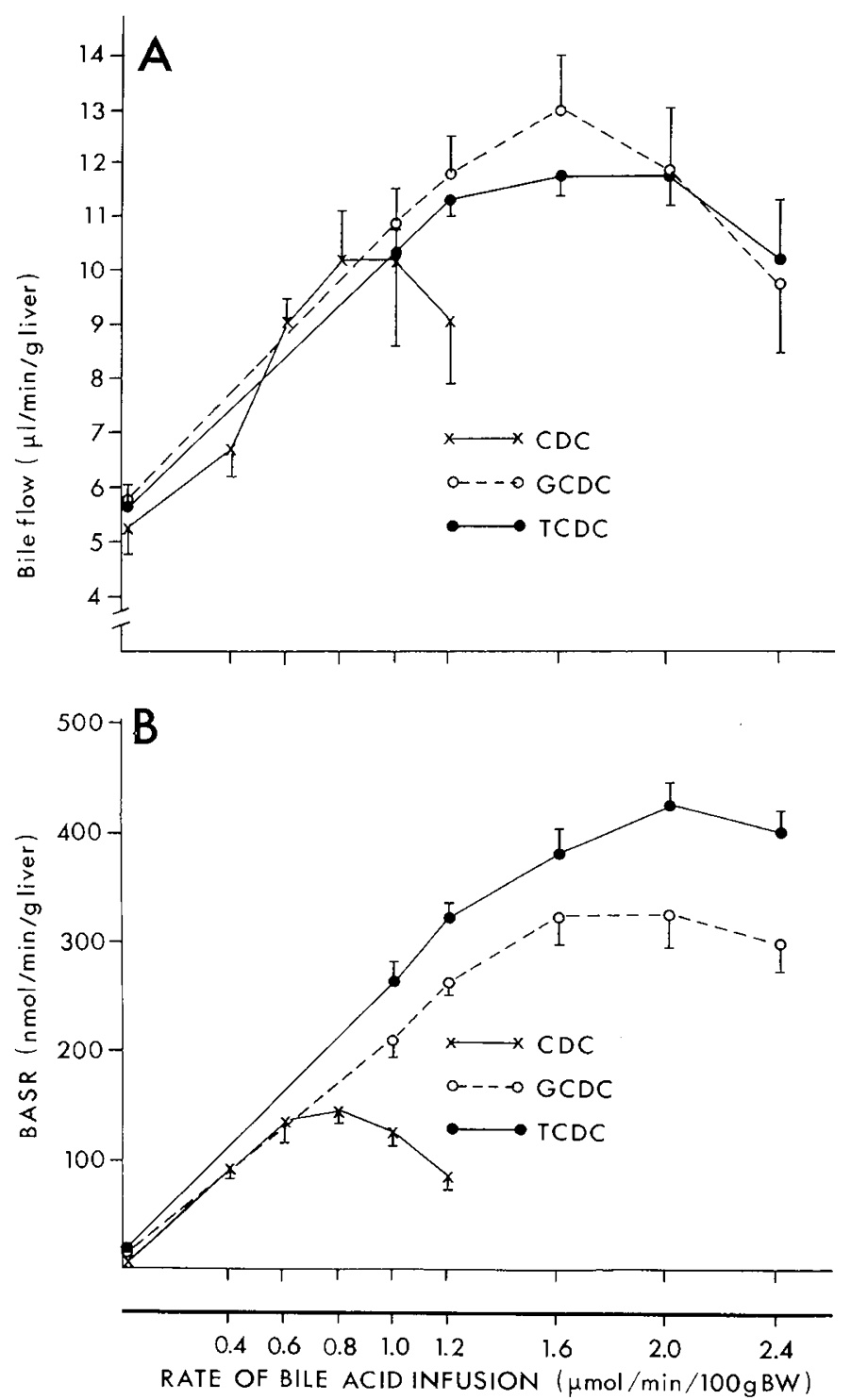

Fig. 1. Bile flow $(A)$ and bile acid secretion rate $(B)$ during infusion of CDC and of its glycine (GCDC) and taurine (TCDC) conjugates administered in step-wise increasing rates to three groups of five guinea pigs. A decrease in bile flow was observed at a lower rate of infusion for the free bile acid than for its two conjugates. Values are expressed as mean $\pm \mathrm{SE}$. The BASR maximum for CDC was reached at a perfusion rate of $0.8 \mu \mathrm{mol} / \mathrm{min} / 100 \mathrm{~g}$ body weight. The corresponding SRm was 1.6 and $2.0 \mu \mathrm{mol} / \mathrm{min} / 100 \mathrm{~g}$ body weight for GCDC and TCDC, respectively. 

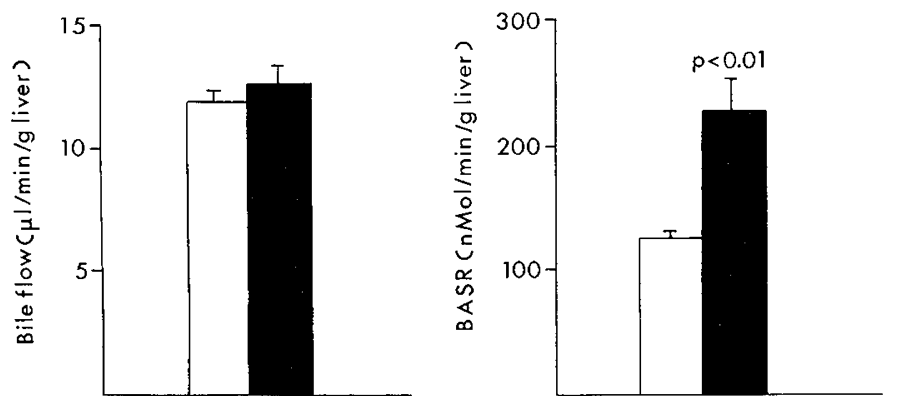

Fig. 2. Bile flow and bile acid secretion rate under the infusion of CDC at a rate of $0.8 \mu \mathrm{mol} / \mathrm{min} / 100 \mathrm{~g}$ body weight corresponding to the BASR maximum in two groups of six guinea pigs on a normal diet with (四) or without $(\square)$ taurine $0.5 \%$ added to the drinking water for 3 days before the experiment. Values are expressed as mean SEM.

percent of free biliary bile acids and the extent of sulfation were not modified by taurine (Fig. 4).

The effects of supplemental taurine on bile flow and BASR in response to the infusion of CDC-conjugates was similar to those observed with CDC in that bile flow was essentially unchanged while BASR was increased. Taurine increased $(p<0.01)$ the BASR from $327 \pm 23$ to $424 \pm 35 \mathrm{nmol} / \mathrm{min} / \mathrm{g}$ liver for an infusion rate of $1.6 \mu \mathrm{mol} / \mathrm{min} / 100 \mathrm{~g}$ body weight of GCDC and from $426 \pm 21$ to $519 \pm 27$ for an infusion rate of $2.0 \mu \mathrm{mol}$; $\mathrm{min} / 100 \mathrm{~g}$ body weight of TCDC.

Table 1 presents the data in animals with and without taurine infused with ${ }^{14} \mathrm{C}-\mathrm{CDC}$ at a rate of $0.8 \mu \mathrm{mol} / \mathrm{min} / 100 \mathrm{~g}$ body weight. The percent of recovered labeled CDC averaged $85 \%$ on and off taurine and the percent of distribution of radioactivity in bile, liver, blood, and urine was similar in the two groups.

\section{DISCUSSION}

This study determined the SRm of CDC and of its glycine and taurine conjugates in guinea pigs and explored the effect of a supplement of taurine on the BASR at the SRm for these three bile acids.

The data showing that the SRm of CDC was 2-fold lower than that of its conjugates confirms previous studies in rats $(12,16$, $18,19,32)$. The difference between the SRm of CDC and of its conjugates may be due to the change in their hydrophilic-hydrophobic balance (33). It is known that the most hydrophilic bile salts have high hepatic secretory maxima, are not cholestatic, have a low hemolytic and detergent potential $(9,10,35)$, and exhibit little cytotoxicity in animals $(12,32,36)$ and in humans (37). There is an exception to this rule in that ursodeoxycholic acid has a very low SRm and yet has a very mild hepatotoxic potential (18). It is of interest to note that TCDC had an SRm that was $30 \%$ higher than that of GCDC. A tendency to a larger BASR was previously noted for tauroconjugates in the guinea pig (38) but this was not documented in hamsters (5). Furthermore, both studies were carried out at low perfusion rates $(0.4$ $\mu \mathrm{mol} / \mathrm{min} / 100 \mathrm{~g}$ body weight).

A daily amount of 200 to $300 \mathrm{mg}$ of taurine fed to guinea pigs which normally conjugate $75 \%$ of their bile acids with glycine is reported to lead to a predominance of taurine over glycine conjugates (39). In our study with taurine there was essentially an equal proportion of glyco and tauroconjugates and the BASR increased by $70 \%$ in response to infusion rates of $C D C$ at the $\mathrm{SRm}$. Conjugation is known to be a mechanism of detoxification of bile acids not only for free (40) but also for sulfated bile acids (25). However, the pattern of conjugation may also be important inasmuch as the cholestatic potential of sulfated lithocholate persists when it is conjugated with glycine but not with taurine (25). Examination of the profile of bile acids recovered in the animals pretreated with taurine and infused with $\mathrm{CDC}$ revealed a 3-fold increase in tauroconjugates in the absence of a significant change in either free or sulfated bile acids. The percent of free bile acids amounted to more than $10 \%$ during the CDC infusion
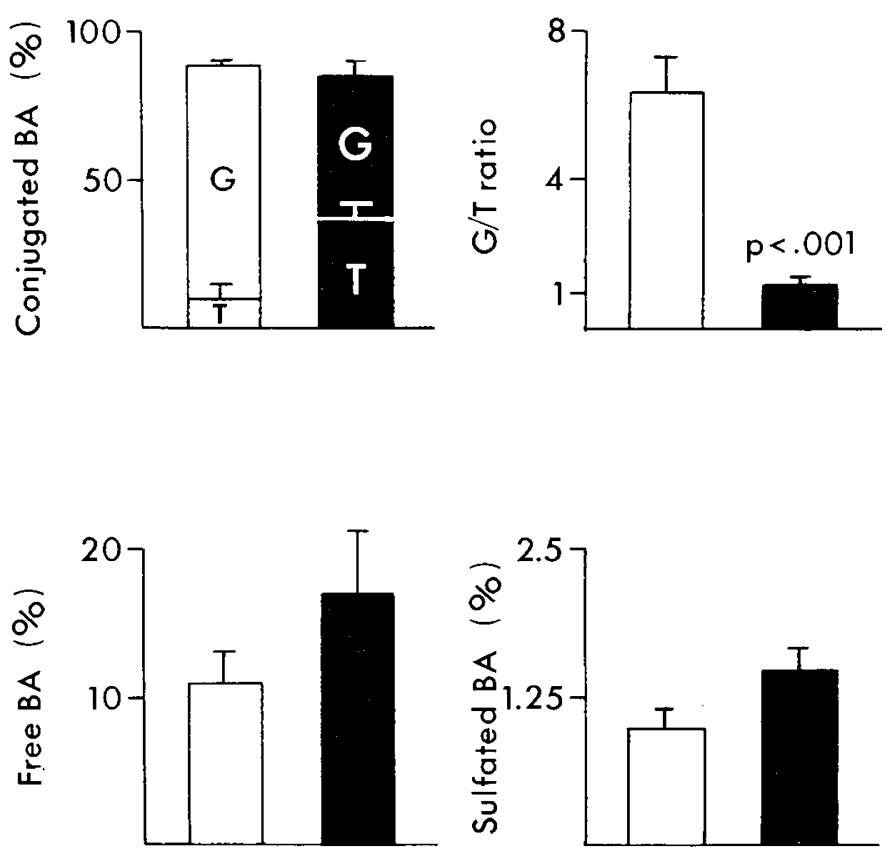

Fig. 3. Pattern of biliary bile acids in guinea pigs infused with $C D C$ at a rate of $0.8 \mu \mathrm{mol} / \mathrm{min} / 100 \mathrm{~g}$ body weight corresponding to the BASR maximum in two groups of three guinea pigs on a normal diet with ( $\mathbf{\square})$ or without $(\square)$ taurine $0.5 \%$ added to the drinking water for 3 days before the experiment. Values are expressed as mean SEM. $G$, glycoconjugates; $T$, tauroconjugates.
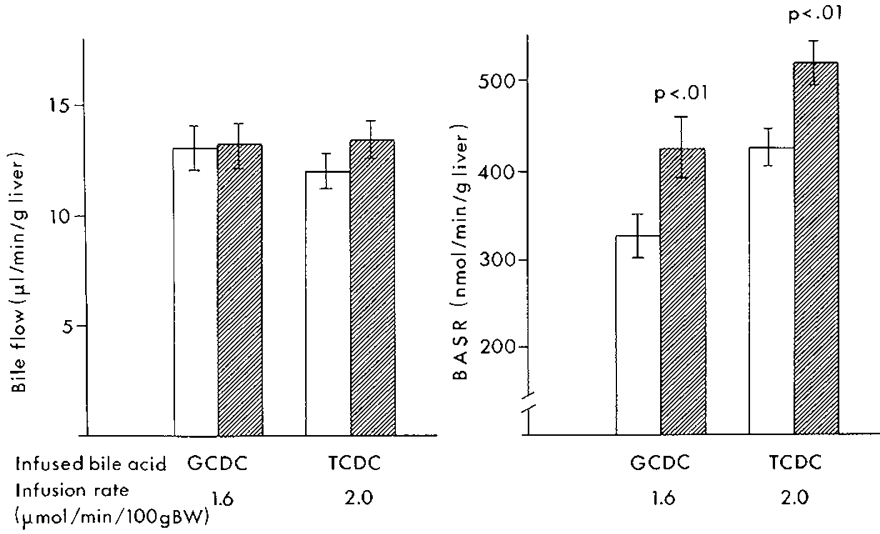

Fig. 4. Bile flow and bile acid secretion rate under the infusion of GCDC and TCDC at rates of 1.6 and $2.0 \mu \mathrm{mol} / \mathrm{min} / 100 \mathrm{~g}$ body weight corresponding to their respective $\mathrm{SRm}$ in two groups of five guinea pigs on a normal diet with $(\mathbb{Z})$ or without $(\square)$ taurine $0.5 \%$ added to the drinking water for 3 days before the experiment. Values are expressed as mean \pm SEM.

Table 1. Distribution of ${ }^{14} C-C D C$ in organs and physiological fluids (mean $\pm S E$ )

\begin{tabular}{lcccc}
\hline & $\begin{array}{c}\text { Bile } \\
(\%)\end{array}$ & $\begin{array}{c}\text { Liver } \\
(\%)\end{array}$ & $\begin{array}{c}\text { Blood } \\
(\%)\end{array}$ & $\begin{array}{c}\text { Urine } \\
(\%)\end{array}$ \\
\hline $\mathrm{CDC}^{*}(n=3)$ & 72.6 & 5.6 & 5.8 & 1.1 \\
& \pm 4.8 & \pm 0.2 & \pm 0.4 & \pm 0.5 \\
$\mathrm{CDC}+$ taurine & 76.5 & 6.3 & 7.8 & 0.11 \\
$(n=3)$ & \pm 6.0 & \pm 1.1 & \pm 0.8 & \pm 0.05 \\
\hline
\end{tabular}

* Intravenous CDC at a rate of $0.8 \mu \mathrm{mol} / \mathrm{min} / 100 \mathrm{~g}$ body weight.

in control animals and increased to $17 \%$ in those with supplemental taurine. This indicates that the availability of large amounts of taurine did not decrease the percent of free bile acids despite the fact that the single transferase conjugation enzyme has a greater affinity for taurine than for glycine (41). Although the extent of sulfation increases with cholestasis (42), bile salt 
sulfotransferase activity has not been found to be inducible (43). Our results tend to support these findings because less than $1.5 \%$ of hepatic biliary bile acids were sulfated in response to CDC administered to animals on and off taurine. It is therefore apparent that the increased bile flow and SRm in response to taurine cannot be accounted by the synthesis of sulfated forms which are more osmotically active and which are known to increase bile flow (44).

The data with labeled CDC show no difference between the distribution of radioactive CDC infused with or without taurine in liver, blood, and bile. This suggests that the sinusoidal uptake and the translocation across the hepatocyte were unlikely limiting steps and that the SRm of CDC was modulated by its transfer across the bile canalicular membrane. These results are in accordance with previous data showing that the maximum capacity for uptake far exceeds the maximum secretory rate $(14,15)$.

The results obtained on the effect of taurine in response to CDC suggests that taurine conjugation accounts for the increased BASR especially since the BASR of TCDC at $0.8 \mu \mathrm{mol} / \mathrm{min} / 100$ g body weight (Fig. $1 B$ ) corresponds to that achieved in animals with $\mathrm{CDC}$ and taurine (Fig. 2). However, taurine conjugation cannot account for the fact that pretreatment with taurine augmented the BASR of both infused GCDC and TCDC. A recent study suggests that taurine feeding not only leads to increased activity of cholesterol $7-\alpha$-hydroxylase but also of HMG CoA reductase activity and results in an increase in BASR (26). A further observation is that taurine favors enhanced low-density lipoprotein receptor binding, internalization, and degradation thereby delivering more cholesterol for bile acid synthesis and secretion (45). It is, therefore, clear that taurine not only increases the availability of cholesterol but also the synthesis of both cholesterol and bile acids. However, the role of taurine on bile acid uptake, their transcellular transport and secretion through the bile canalicular membrane deserves further exploration.

Our observations show that free CDC had a two-fold lower $\mathrm{SRm}$ than glycine and taurine conjugates in the guinea pig and that, in response to taurine, there was an increase in the BASR not only of the free bile acid but also of its two conjugates. We can hypothesize that taurine modulates the SRm of bile acids by facilitation of bile canalicular excretion that may, only in part, be accounted by a change in the conjugation pattern.

Acknowledgment. The authors thank Mrs. D. St-Cyr Huot for her secretarial assistance.

\section{REFERENCES}

1. Blitzer BL, Boyer JL 1982 Cellular mechanisms of bile formation. Gastroenterology $82: 346-357$

2. Erlinger S 1982 Hepatocyte bile secretion: current views and controversies. Hepatology 4:352-359

3. Scharschmidt BF, Van Dyke RW 1983 Mechanisms of hepatic electrolyte transport. Gastroenterology 85:1199-1214

4. Wheeler HO 1968 Water and electrolytes in bile. In: Code CF, Heidel W (eds) Handbook of Physiology. American Physiology Society, Washington, D.C. pp 2409-2432

5. Gurantz D, Hofmann AF 1984 Influence of bile acid structure on bile flow and biliary lipid secretion in the hamster. Am J Physiol 247:G736-G748

6. O'Maille ERL, Kozmary SV, Hofmann AF, Gurantz D 1984 Differing effects of norcholate and cholate on bile flow and biliary lipid secretion in the rat. Am J Physiol 246:G67-G71

7. Tavoloni N, Sarkozi L, Jones MJT 1985 Choleretic effects of differently structured bile acids in the guinea pig. Proc Soc Exp Biol Med 178:60-67

8. Tavoloni N 1984 Permeation patterns of polar nonelectrolytes across the guinea pig biliary tree. Am J Physiol 247:G527-G536

9. Yousef IM, Barnwell S, Gratton F, Tuchweber B, Weber A, Roy CC 1987 Liver cell membrane solubilization may control maximum secretory rate of cholic acid in the rat. Am J Physiol 252:G84-G91

10. Yousef IM, Barnwell S, Tuchweber B, Weber A, Roy CC 1987 Effect of complete sulfation of bile acids on bile formation in rats. Hepatology 7:535542

11. Hall TJ, Baker AL, Cooper MJ, Moossa AR 1979 Choleresis and cholestasis produced by infusion of taurocholic acid or taurodehydrocholic acid combined with BSP in the rhesus monkey. Dig Dis Sci 24:350-357

12. Hardison WGM, Hatoff DE, Miyai K, Weiner RG 1981 Nature of bile acid maximum secretory rate in the rat. Am J Physiol 241:G337-G343

13. Paumgartner G, Santer K, Schwarz HP, Herz R 1973 Hepatic excretory transport maximum for free and conjugated cholate in the rat. In: Paum- gartner G, Preisig R (eds) The Liver: Quantitative Aspects of Structure and Function. Karger, Basel, pp 337-344

14. Glasinovic JC, Dumont M, Duval M, Erlinger S 1975 Hepatocellular uptake of taurocholate in the dog. J Clin Invest 55:419-426

15. Reichen J, Paumgartner G 1975 Kinetics of taurocholate uptake by the perfused rat liver. Gastroenterology 68:132-136

16. Drew R, Priestly BG 1979 Choleretic and cholestatic effects of infused bile salts in the rat. Experientia 35:809-811

17. Herz R, Paumgartner G, Preisig R 1976 Inhibition of bile formation by high doses of taurocholate in the perfused rat liver. Scand $\mathrm{J}$ Gastroenterol 11:741746

18. Zouboulis-Vafiadis I, Dumont M, Erlinger S 1982 Conjugation is rate limiting in hepatic transport of ursodeoxycholate in the rat. Am J Physiol 243:G208G213

19. Erlinger S, Dumont M, Zouloulis-Vafiadis I, De Couet G 1984 The importance of conjugation in biliary secretion of ursodeoxycholate and 7-ketolithocholate in the rat. Clin Sci 66:487-491

20. Gaull GE 1983 Taurine in human milk: growth modulator or conditionally essential amino acid? J Pediatr Gastroenterol Nutr 2(suppl):S266-S271

21. Thurston JH, Hauhart RE, Naccarto EF 1981 Taurine: possible role in osmotic regulation of mammalian heart. Science 214:1373-1374

22. Pasantes-Morales H, Arzate NE, Cruz C 1982 The role of taurine in nervous tissue. In: Huxtable RJ, Pasantes-Morales $\mathrm{H}$ (eds) Taurine in Nutrition and Neurology. Adv Exp Med Biol 139:273-292

23. Sturman JA, Rassin DK, Hayes KC 1978 Taurine deficiency in the kitten: exchange and turnover of $\left({ }^{35} \mathrm{~S}\right)$ taurine in brain, retina, and other tissues. $\mathrm{J}$ Nutr 108:1462-1476

24. Gaull GE, Wright CE, Tallan HH 1983 Taurine in human lymphoblastoid cells: uptake and role in proliferation. In: Kuriyama K, Huxtable RJ (eds) Sulfur Amino Acids: Biochemical and Clinical Aspects. Alan R Liss, New York, pp 297-303

25. Dorvil NP, Yousef IM, Tuchweber B, Roy CC 1983 Taurine prevents cholestasis induced by lithocholic acid sulfate in guinea pigs. Am J Clin Nutr 37:221-232

26. Bellentani S, Pecorari M, Cordoma P, Marchegiano P, Manenti F, Bosisio E, De Fabiani E, Galli $G 1987$ Taurine increases bile acid pool size and reduces bile saturation index in the hamster. J Lipid Res 28:1021-1027

27. Belli DC, Levy E, Darling P, Leroy C, Lepage G, Giguère R, Roy CC 1987 Taurine improves the absorption of a fat meal in patients with cystic fibrosis. Pediatrics 80:517-523

28. Weber AM, Chartrand L, Doyon G, Gordon S, Roy CC 1972 The quantitative determination of fecal bile acids in children by the enzymatic method. Clin Chim Acta 39:524-531

29. Parmentier G, Eyssen H 1977 Synthesis and characteristics of the specific monosulfates of chenodeoxycholate, deoxycholate and their taurine or glycine conjugates. Steroids 30:583-590

30. Lillington JM, Trafford DJH, Makin HLJ 1981 A rapid and simple method for the esterification of fatty acids and steroid carboxylic acids prior to gasliquid chromatography. Clin Chim Acta 111:91-98

31. Winer BJ 1971 Statistical Principles in Experimental Design. McGraw Hill, New York, pp 208-209

32. Kitani K, Kanai S 1985 Ursodeoxycholate-induced choleresis in taurinedeprived and taurine-supplemented rats. Jpn J Physiol 35:443-462

33. Armstrong MJ, Carey MC 1982 The hydropobic-hydrophilic balance of bile salts. Inverse correlation between reverse-phase high performance liquid chromatographic mobilities and micellar cholesterol-solubilizing capacities. J Lipid Res 23:70-80

34. Carey MC 1982 The enterohepatic circulation. In: Arias IM, Popper $H$ Schachter D, Shafritz DA (eds) The Liver: Biology and Pathobiology. Raven Press, New York, pp 429-465

35. Leighton LS, Carey MC 1984 Bile salt hydrophilicity determines whether the physical state of native hepatic bile is predominantly vesicular or micellar. Gastroenterology 86:1157(abstr)

36. Shefer S, Zaki FG, Salen G 1983 Early morphologic and enzymatic changes in livers of rats treated with chenodeoxycholic and ursodeoxycholic acids. Hepatology 3:201-208

37. Phillips MJ, Fisher RL, Anderson DW, Lan SP, Lanchin JM, Boyer JL 1983 Ultrastructural evidence of intrahepatic cholestasis before and after chenodeoxycholic acid therapy in patients with cholelithiasis: the national cooperative gallstone study. Hepatology 3:209-220

38. Tavoloni N 1986 Bile acid structure and bile formation in the guinea pig. Biochim Biophys Acta 879:186-201

39. Kibe A, Wake C, Kuramoto T, Hoshita $\Upsilon 1980$ Effect of dietary taurine on bile acid metabolism in guinea pigs. Lipids 15:224-229

40. Palmer RH 1979 Bile acid heterogeneity and the gastrointestinal epithelium: from diarrhea to colon cancer. J Lab Clin Med 94:655-660

41. Vessey DA 1978 The biochemical basis for the conjugation of bile acids with either glycine or taurine. Biochem J 174:621-626

42. Stiehl A, Ast E, Czygan P 1978 Pool size, synthesis, and turnover of sulfated and nonsulfated cholic acid and chenodeoxycholic acid in patients with cirrhosis of the liver. Gastroenterology 74:572-577

43. Balistreri WF, Zimmer L, Suchy FJ, Bove KE 1984 Bile salt sulfotransferase: alterations during maturation and non-inducibility during substrate ingestion. J Lipid Res 25:228-235

44. Donovan JM, Yousef IM, Carey MC 1984 Complete sulfation of the common bile salts of man: synthesis, properties and interactions with lecithin. Gastroenterology 86:1064(abstr)

45. Zouhair F, Stephan ZF, Lindsey S, Hayes KC 1987 Taurine enhances low density lipoprotein binding. J Biol Chem 262:6069-6073 